\title{
Expression of prothymosin $\alpha$ in lung cancer is associated with squamous cell carcinoma and smoking
}

\author{
YU-HSUAN KUO ${ }^{1,2}$, AI-LI SHIAU ${ }^{3}$, CHAO-LING TUNG ${ }^{1}$, YU-CHU SU ${ }^{4}$, CHIEN-FENG LI $^{5}$,

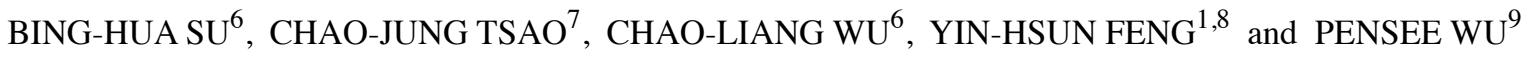 \\ ${ }^{1}$ Division of Hematology and Oncology, Department of Internal Medicine, Chi-Mei Medical Center, \\ Tainan 71004; ${ }^{2}$ College of Pharmacy and Science, Chia Nan University, Tainan 71710; \\ ${ }^{3}$ Department of Microbiology and Immunology, National Cheng Kung University Medical College; \\ ${ }^{4}$ Department of Otolaryngology, National Cheng Kung University Hospital, Medical College, \\ National Cheng Kung University, Tainan 70101; ${ }^{5}$ Department of Pathology, Chi-Mei Medical Center, Yong Kang, \\ Tainan 71004; ${ }^{6}$ Department of Biochemistry and Molecular Biology, National Cheng Kung University \\ Medical College, Tainan 70101; ${ }^{7}$ Division of Hematology and Oncology, Chi-Mei Medical Center, Tainan 73657; \\ ${ }^{8}$ Department of Nursing, Chung Hwa University of Medical Technology, Tainan 71703, Taiwan, R.O.C.; \\ ${ }^{9}$ Institute of Reproductive and Developmental Biology, Imperial College London, London W12 ONN, UK
}

Received March 24, 2018; Accepted January 11, 2019

DOI: $10.3892 / 01.2019 .10248$

\begin{abstract}
Prothymosin $\alpha(\operatorname{ProT} \alpha)$ is a nuclear protein that serves a role in oncogenesis, by promoting proliferation and inhibiting apoptosis in various malignancies. The present study was designed to investigate ProT $\alpha$ expression in resected human non-small cell lung cancer to define the clinicopathological associations of ProT $\alpha$-positive lung cancer. Immunohistochemical staining of ProT $\alpha$ was performed using tumor sample slides from 149 patients with non-small cell lung cancer, who underwent surgical resection. Association between the expression of ProT $\alpha$ and the following clinicopathological parameters was accessed: Age, sex, stage, lymph node involvement, pathological subtype, recurrence and cigarette smoking. A total of 85 tumors (57\%) were classified as ProT $\alpha$-positive lung cancer by staining intensity and 73 tumors $(49 \%)$ were regarded as ProT $\alpha$-positive by scoring index. The majority of patients with $P$ roT $\alpha$-positive tumors were younger $(\mathrm{P}=0.05)$ and had squamous cell carcinoma $(\mathrm{P}<0.01)$ compared with older and adenocarcinoma. Positive expression of ProT $\alpha$ by staining intensity was associated with a higher incidence rate of cancer recurrence $(\mathrm{P}=0.05)$ compared with negative $\mathrm{ProT} \alpha$
\end{abstract}

Correspondence to: Dr Yin-Hsun Feng, Division of Hematology and Oncology, Department of Internal Medicine, Chi-Mei Medical Center, 901 Chung-Hwa Road, Tainan 71004, Taiwan, R.O.C.

E-mail: yinhsun.feng@gmail.com

Professor Chao-Liang Wu, Department of Biochemistry and Molecular Biology, National Cheng Kung University Medical College, Tainan, 1 University Road, Tainan 70101, Taiwan, R.O.C.

E-mail: wumolbio@mail.ncku.edu.tw

Key words: prothymosin $\alpha$, lung cancer, squamous cell carcinoma, cigarettes expression. ProT $\alpha$ was also associated with cigarette smoking, particularly in the group with squamous cell carcinoma. Therefore, the present data suggested that ProT $\alpha$-positive non-small cell lung cancer was associated with younger patients, squamous cell carcinoma, cigarette smoking and a higher incidence recurrence rate, subsequently indicating a subtype consisting of patients with smoking-associated inferior outcomes.

\section{Introduction}

Prothymosin $\alpha(\operatorname{ProT} \alpha)$ is a $12.5 \mathrm{kDa}$ acidic nuclear protein, initially isolated from rat thymus as the putative precursor of thymosin $\alpha 1$, and is regarded as a thymic immunoregulatory hormone (1). The biological function of ProTa contributes to cell cycle regulation, transcription, proliferation and apoptosis (2-4). The ProT $\alpha$ gene is upregulated by MYC proto-oncogene, BHLH transcription factor (c-Myc), E2F transcription factor 1 and the human papilloma virus type 16 E6 oncogene, whereas ProT $\alpha$ is downregulated by the p53 tumor suppressor (5). In addition, ProT $\alpha$ is present only in cells that are in the proliferative cycle, and therefore, is not expressed in non-proliferative cells (5). In colon cancer cells, ProT $\alpha$ mRNA expression has been reported to be positively correlated with $c$-myc, and its expression level was higher in the tumor tissue compared with the adjacent normal tissue (6). Overexpression of ProTa has been associated with a poor prognostic outcome in urinary tract transitional cell carcinoma, head and neck cancer, hepatocellular carcinoma and colon cancer (7-10). However, to the best of our knowledge, studies on the association between ProT $\alpha$ and lung carcinogenesis are limited. Previous study has indicated that the secreted thymosin- $\alpha 1$ in plasma from patients with lung cancer was higher compared with healthy individuals, but was not associated with age or pathological subtype of lung cancer in the first human lung 
cancer study (11). In a urethane injection carcinogenesis A/J mouse model, daily administration of thymosin- $\alpha 1$ significantly reduced lung adenoma multiplicity, providing a different biological perspective on ProTa (12). A study of 20 lung cancer tissues reported that overexpression of ProT $\alpha$ mRNA was associated with poor prognosis (13).

Our previous research focused on the contribution of ProT $\alpha$ to the acetylation of histone and nuclear factor $-\kappa \mathrm{B}$, and particularly on smoke exposure (14). ProT $\alpha$ transgenic mice are prone to develop emphysema when exposed to cigarette smoke extract (14). However, the association of lung cancer with ProT $\alpha$, in terms of cigarette exposure and pathological subtypes, has not been well defined (14). The aim of the present study was to investigate the impact of ProT $\alpha$ on pathological subtypes and clinical parameters in patients with lung cancer.

\section{Materials and methods}

Patient characteristics. A total of 149 patients (mean, 66; range, 28-90 years), including 87 male and 62 female patients, with a pathological diagnosis of lung carcinoma were included in the present study. Lung metastasis from other primary site was excluded. The lung cancer tissues were harvested between 1997 and 2008 by surgical resection at Chi-Mei Medical Center (Yong Kang, Taiwan). Data on parameters including age, sex, operative procedure, recurrence, disease-free survival, pathological subtypes of lung carcinoma and history of cigarette smoking were collected from the patients' medical records (Table I).

Immunohistochemistry stain. Immunohistochemistry staining of $5 \mu \mathrm{m}$ thick paraffin-embedded sections was carried out using the 2-step protocol Novolink Polymer Detection System (Leica Microsystems. Ltd., Milton Keynes, UK), according to the manufacturer's protocols. In brief, the sections were first deparaffinized in xylene two times for $5 \mathrm{~min}$ to remove paraffin and subsequently rehydrated through a gradient of ethanol for $3 \mathrm{~min}$ in each concentration, 100, 100, 95, 70 and $50 \%$, followed by de-ionized water. Following microwave $10 \mathrm{mM}$ sodium citrate buffer ( $\mathrm{pH}$ 6.0) boiled for $10 \mathrm{~min}$, slides were washed for 5 min $\mathrm{x} 2$ in PBS. Endogenous peroxidase was neutralized using a peroxidase block ( $3.5 \%$ hydrogen peroxide) for $5 \mathrm{~min}$. Following incubation for $1 \mathrm{~h}$ at room temperature, the sections were washed three times in PBS for 5 min each. Subsequently, the slides were treated with $1 \%$ skimmed milk in PBS for $30 \mathrm{~min}$ at room temperature, and non-specific background staining was minimized further by incubation in $0.3 \%$ bovine serum albumin (Gibco; Thermo Fisher Scientific, Inc., Waltham, MA, USA) in $0.1 \mathrm{M}$ Tris-buffered saline for $1 \mathrm{~h}$ at room temperature. Sections were incubated with antibody diluent (Dako; Agilent Technologies, Inc., Santa Clara, CA, USA) for $1 \mathrm{~h}$ at room temperature and washed again in PBS in triplicate for 5 min each. The primary monoclonal antibody used was anti-human-prothymosin $\alpha$ antibody (4f4 clone; culture supernatant generated from Professor Chao-Liang Wu's lab according to references) $(15,16)$. Following serial incubation with the primary antibody overnight at $4^{\circ} \mathrm{C}$, the sections were washed in triplicate with PBS for $5 \mathrm{~min}$ each, and incubated with goat anti-mouse IgG-HRP (115-035-003, dilution, 1:300; Jackson ImmunoResearch Laboratories, Inc., West Grove, PA,
Table I. Clinicopathological parameters of the present study population.

\begin{tabular}{lr}
\hline Parameter & $\mathrm{n}=149$ \\
\hline Median age (range), years & $66(28-90)$ \\
Sex $(\%)$ & \\
Male & $87(58)$ \\
Female & $62(42)$ \\
Pathological subtype $(\%)$ & \\
Squamous cell carcinoma & $30(20)$ \\
Adenocarcinoma & $119(80)$ \\
Tumor stage $(\%)($ TNM system) $(17)$ & \\
I & $79(53)$ \\
II & $35(24)$ \\
III & $32(21)$ \\
IV & $3(2)$ \\
Cigarette smoking $(\%)$ & \\
Yes & $23(15)$ \\
No & $126(85)$ \\
Intensity of ProT $\alpha$ expression $(\%)$ & \\
Negative & $22(15)$ \\
Weak & $63(42)$ \\
Moderate & $33(22)$ \\
Strong & $31(21)$ \\
ProT $\alpha$ score $(\%)$ & \\
$>50$ & $73(49)$ \\
& \\
&
\end{tabular}

ProT $\alpha$, prothymosin $\alpha$.

USA) for $2 \mathrm{~h}$ at room temperature. Following incubation, the slides were washed five times in PBS for 5 min each. Negative controls included sections stained with mouse universal negative control with the same concentration of primary antibodies (Dako; Agilent Technologies, Inc.) overnight at $4^{\circ} \mathrm{C}$. Reactivity was visualized with DAB Quanto (Thermo Fisher Scientific, Inc.) and counterstained with hematoxylin (MUTO, 5X dilution) for $10 \mathrm{~min}$ at room temperature. The sections were washed in $\mathrm{di}-\mathrm{H}_{2} \mathrm{O}$ for $10 \mathrm{~min}$ prior to dehydration, clearing and mounting. Slide scorings were based on intensity of stain as follows: 0, negative; 1 , weak; 2, moderate; 3, strong Fig. 1) and percentage of area stained (0-100\%), with both scores multiplied to yield the total score. The definition of a high ProT $\alpha$ score was $>50$. The results were interpreted by light microscope under the power of $\mathrm{x} 100$.

Statistical analysis. All statistical analyses were performed using SigmaStat 3.5 software (Systat Software, Inc., San Jose, CA, USA). The unpaired t-test and $\chi^{2}$ test were used to evaluate the differences in discrete variables and continuous variables between the expression of ProT $\alpha$ and the clinicopathological parameters. Values are presented as the mean \pm standard deviation. For disease-free survival, the Kaplan-Meier method was adapted to generate survival curves, and the log-rank test 
A

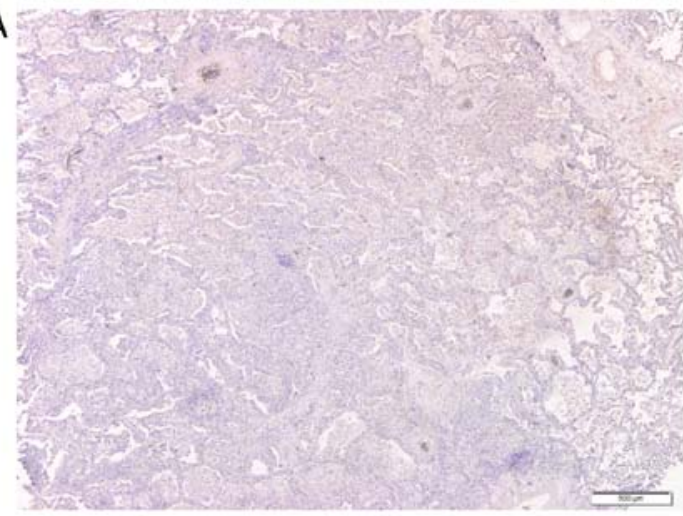

B

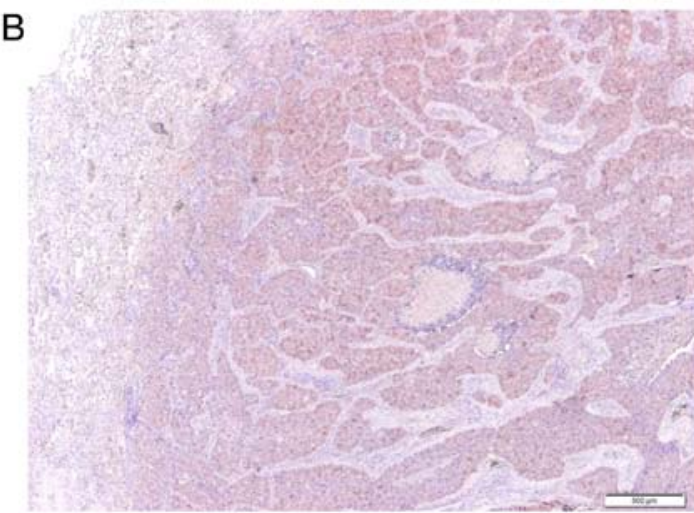

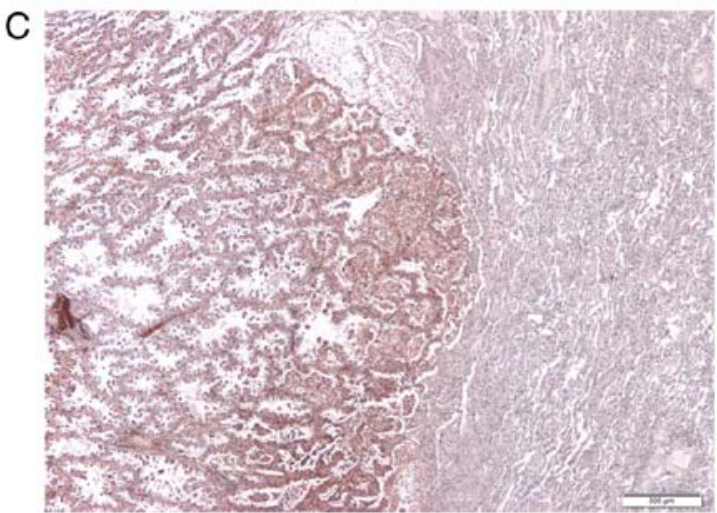

$\mathrm{D}$

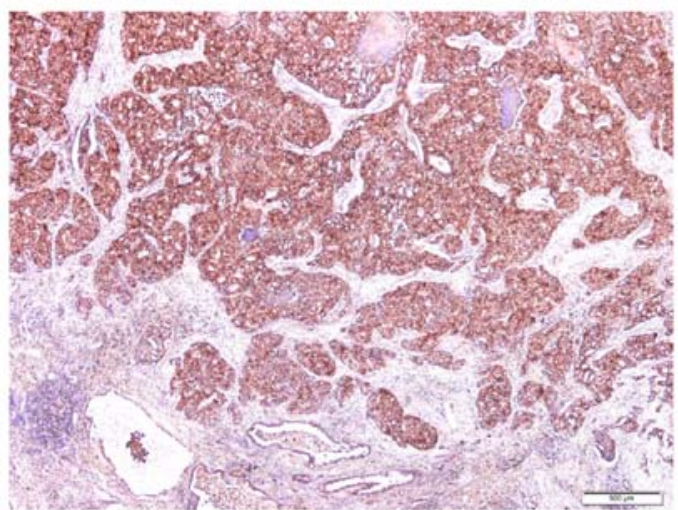

Figure 1. Expression of Prothymosin $\alpha$ by immunohistochemistry stain in patients with non-small cell lung cancer observed by light microscope under the power of x100 magnification. (A) Negative stain. (B) Weak stain. (C) Moderate stain and (D) strong stain.

was used to estimate the differences. All tests were two-tailed, and $\mathrm{P}<0.05$ was considered to indicate a statistically significant difference.

\section{Results}

Patient demography. A total of 149 patients with resected lung cancer were enrolled for the present study between September 1998 and September 2008. Participating patients did not receive adjuvant chemotherapy, since adjuvant chemotherapy was not the recommended treatment at the time of diagnosis (1998-2008) or in that physical condition of poor performance status or significant organ dysfunction. Patients, who had undergone peri-operative radiotherapy were excluded. The median age of these patients was 66 years (range, 28-90); there were 87 male and 62 female patients. Regarding pathological subtypes, 30 cases were squamous cell carcinoma and 119 cases were adenocarcinoma. A total of 79 cases were stage 1, 35 cases were stage 2, 32 cases were stage 3 and 3 cases were stage 4 by TNM system (based on 6th edition of cancer staging manual, American Joint Committee on Cancer) (17). The 3 patients with stage 4 underwent operation for primary lung tumor and distant metastasis, due to solitary metastasis. Primary lung cancer resection with metastasectomy was suggested in the aforementioned conditions, based on the decision of the physicians at Chi-Mei Medical Center. The majority of the cases, 126, had no history of cigarette smoking, while 23 cases presented with a smoking history. A total of two methods were used to measure the expression of ProTa: staining intensity and the percentage of area stained. The results of staining intensity indicated that the expression of ProT $\alpha$ was negative in 22 cases, weak in 63 cases, moderate in 33 cases and strong in 31 cases. Using the scoring system described above for the percentage of area stained, 76 cases had a high ProTa score (score $>50$; Table I). Nuclear and nucleo-cytoplasmic staining of ProT $\alpha$ were regarded as positive for ProT $\alpha$ expression. However, in the present study, sole nuclear stain of ProT $\alpha$ was rare.

ProTa expression and clinicopathological parameters. In order to verify the association between clinicopathological characteristics and the expression of ProT $\alpha$, the following parameters were assessed: Age, sex, pathological subtype, stage, disease recurrence and cigarette smoking. Using the ProTa scoring system, squamous cell carcinoma and cigarette smoking were the only 2 parameters that were significantly associated with a high ProTa score (Fig. 2). Patients with recurrence of lung cancer tended to have a higher ProT $\alpha$ score, however, the result was not statistical significant. Although cigarette smoking was associated with a high ProTa score in the analysis of these 149 patients, only 20\% (30 cases) had squamous cell carcinoma and $18 \%$ cigarette exposure (23 cases), which may render difficult an accurate interpretation of the contribution of ProT $\alpha$ relative to cigarette smoking and pathological subtypes. The results of the association between clinicopathological parameters and ProTa expression are presented in Table II. Further, the association of ProT $\alpha$ expression with cigarette smoking was evaluated in patients with squamous cell carcinoma or adenocarcinoma. It was indicated that the ProT $\alpha$ score was higher among patients with exposure to cigarettes compared among patients without 
Table II. Association between clinicopathological parameters and ProT $\alpha$ expression.

\begin{tabular}{|c|c|c|c|c|}
\hline Parameter (number) & $\begin{array}{c}\text { Positive ProT } \alpha \text { expression by } \\
\text { intensity }(\%)\end{array}$ & P-value & High ProT $\alpha$ score $(>50)(\%)$ & P-value \\
\hline Age, years & & 0.05 & & 0.04 \\
\hline$\leq 65(67)$ & $34(51)$ & & $40(60)$ & \\
\hline$>65(82)$ & $30(37)$ & & $35(43)$ & \\
\hline Sex & & 0.90 & & 0.69 \\
\hline Male (87) & $37(43)$ & & $42(48)$ & \\
\hline Female (62) & $27(44)$ & & $34(55)$ & \\
\hline Stage (TNM system) & & 0.49 & & 0.22 \\
\hline I (79) & $36(46)$ & & $44(56)$ & \\
\hline II/III/IV (70) & $28(40)$ & & $32(46)$ & \\
\hline Lymph node involvement & & 0.58 & & 0.49 \\
\hline Negative (94) & $42(45)$ & & $50(53)$ & \\
\hline Positive (55) & $22(40)$ & & $26(47)$ & \\
\hline Pathological subtype & & $<0.01$ & & $<0.01$ \\
\hline Squamous cell carcinoma (30) & $23(77)$ & & $24(80)$ & \\
\hline Adenocarcinoma (119) & $41(34)$ & & $52(44)$ & \\
\hline Recurrence & & 0.05 & & 0.42 \\
\hline Negative (112) & $43(38)$ & & $55(49)$ & \\
\hline Positive (37) & $21(57)$ & & $21(57)$ & \\
\hline Cigarette smoking & & 0.61 & & 0.90 \\
\hline Negative (126) & $53(42)$ & & $64(51)$ & \\
\hline Positive (23) & $11(48)$ & & $12(52)$ & \\
\hline
\end{tabular}

ProT $\alpha$, prothymosin $\alpha$.
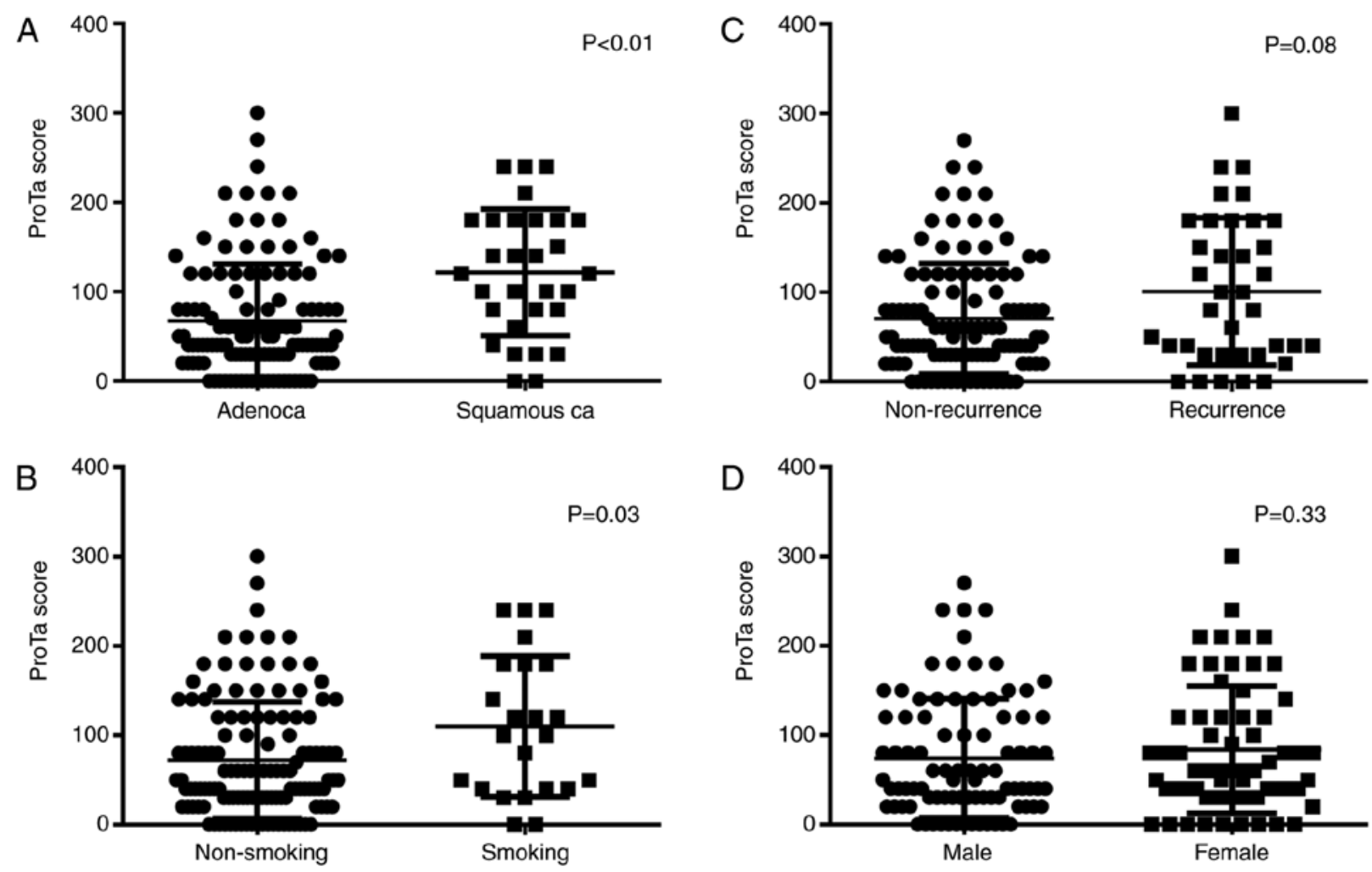

Figure 2. Expression of ProTa score by clinicopathological parameters. Expression of ProT $\alpha$ score in (A) adenocarcinoma and squamous cell carcinoma, (B) non-smoking and smoking (C) non-recurrence and recurrence, and (D) male and female. ProTa, prothymosin $\alpha$. 

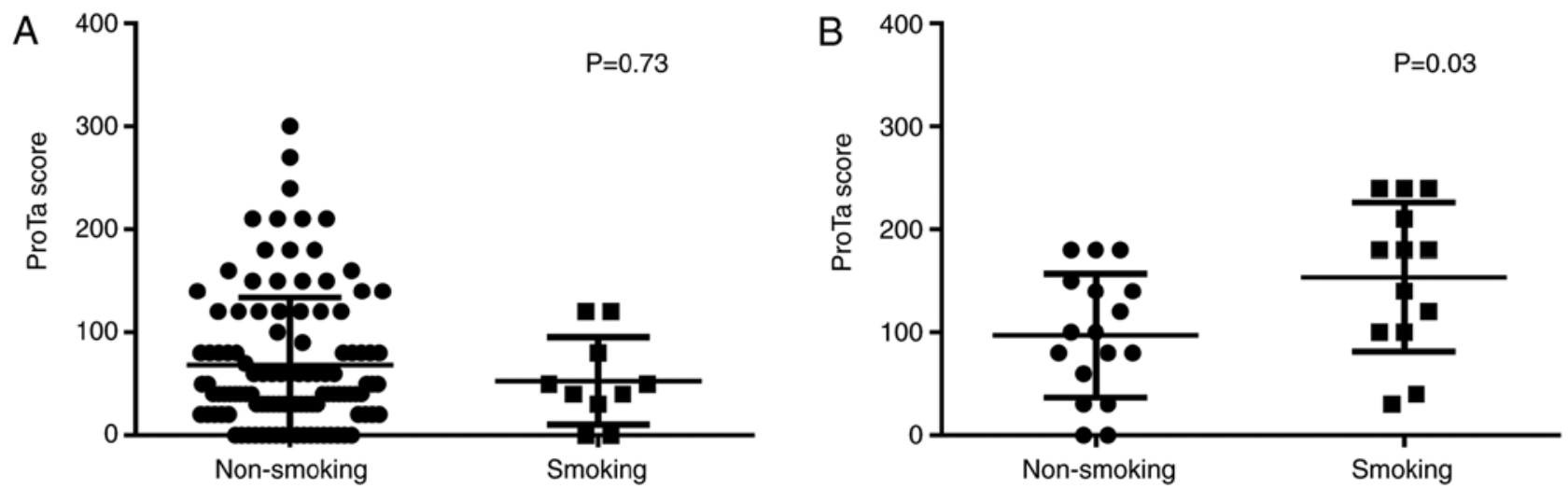

Figure 3. Expression of ProT $\alpha$ score categorized by pathological type for non-smoking and smoking status. ProT $\alpha$ score categorized by non-smoking and smoking in (A) adenocarcinoma and (B) squamous cell carcinoma. prothymosin $\alpha$.
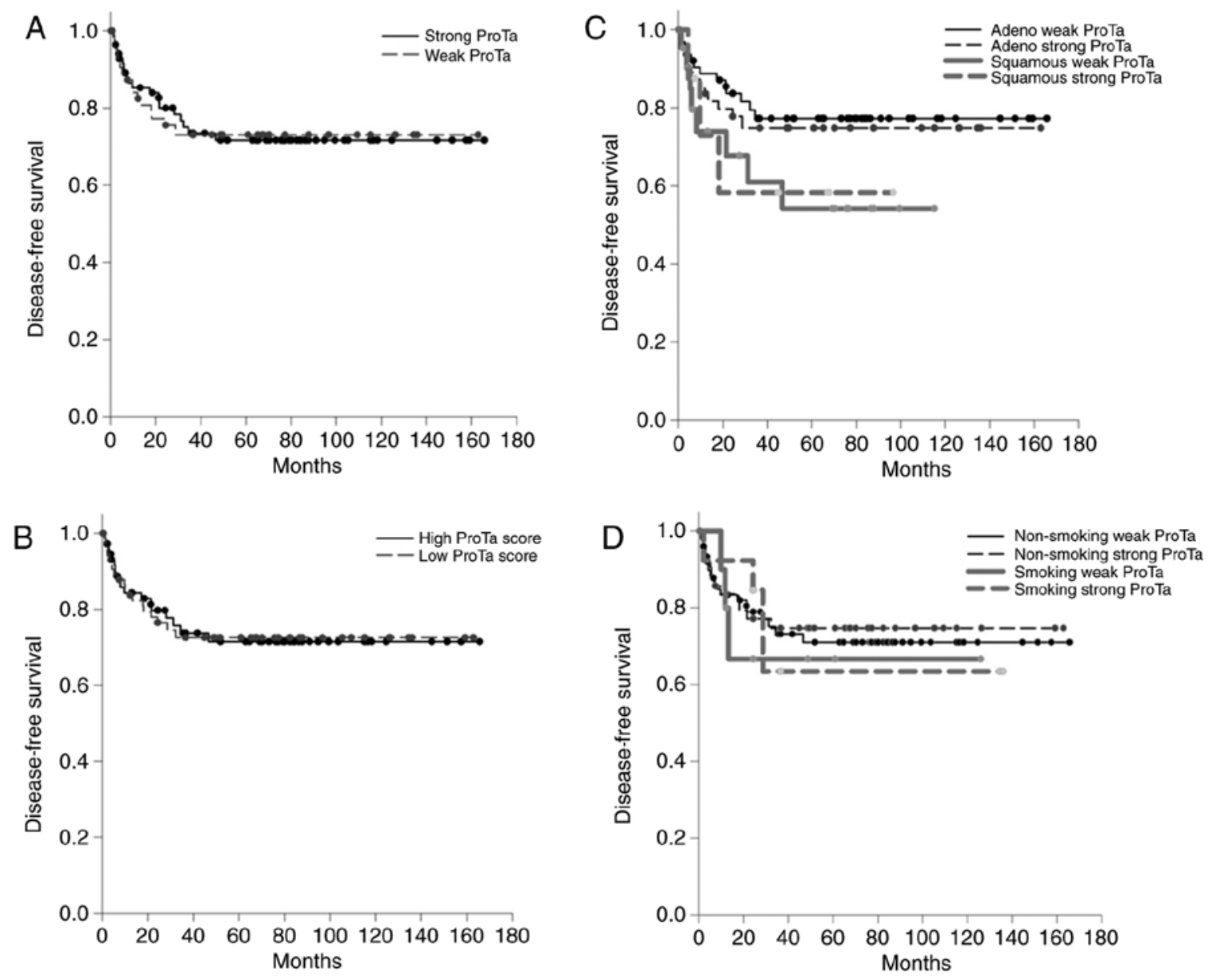

Figure 4. Disease-free survival categorized by ProT $\alpha$ expression and parameters. Kaplan- Meier survival plots for (A) positive and negative ProT $\alpha$ expression according to staining intensity, (B) high and low by ProTa score with a cut-off value of 50, (C) pathological subtypes and staining intensity of ProT $\alpha$ expression and (D) smoking and staining intensity of ProT $\alpha$ expression. Adeno, adenocarcinoma; Squamous, squamous cell carcinoma; ProT $\alpha$, prothymosin $\alpha$.

exposure to cigarettes in the squamous cell carcinoma group $(\mathrm{P}=0.03)$, however, this was not the case in the adenocarcinoma group ( $\mathrm{P}=0.73)$ (Fig. 3). These results indicate that ProTa may serve a role in cigarette smoking-mediated carcinogenesis.

Survival analysis of patients with lung cancer. In a previous study with 20 cases of lung cancer, it was suggested that the presence of ProT $\alpha$ may be a poor prognostic factor for lung cancer (13). In the present study, involving 149 patients with lung cancer with operable disease, neither ProT $\alpha$ expression intensity nor ProTa expression score was associated with disease-free survival (Fig. 4A and B). Following categorization by pathological subtypes of adenocarcinoma and squamous cell carcinoma, squamous cell carcinoma was indicated to be associated with poor disease-free survival compared with cases of adenocarcinoma. However, patients who smoked and 
exhibited strong ProT $\alpha$ expression tended to have the poorest disease-free survival rate. However, the difference between the disease-free survival rate of patients with different ProT $\alpha$ expressions and cigarette exposure statuses was not statistically significant (Fig. 4C and D).

\section{Discussion}

To the best of our knowledge, there have been no previous studies that focus on the protein expression of ProT $\alpha$ in human lung cancer. The mRNA expression of a small group of patients with lung cancer has been investigated, however, the ProT $\alpha$ mRNA levels were not associated with stage or pathological subtype (13). Our previous findings suggested that ProT $\alpha$ was positively correlated with the severity of emphysema in ProT $\alpha$ transgenic mice and patients with emphysema (14). ProT $\alpha$ transgenic mice were susceptible to cigarette smoking extract-induced emphysema mainly due to the inhibition of histone deacetylases and the promotion of matrix metalloproteinase 2 and matrix metalloproteinase 9 (14). As a result, the association between ProT $\alpha$ and cigarette smoking requires further attention.

Cigarette smoking has been reported to have a stronger association with squamous cell carcinoma compared with adenocarcinoma (18). Aside from lung cancer, ProT $\alpha$ has been used to distinguish oral pre-malignant lesions from histologically normal oral tissues by tissue proteomic analysis (19). Overexpression of ProT $\alpha$, as detected by immunohistochemistry, has been reported to have a positive correlation with nuclear staining of tumor at an advanced stage, nodal involvement and inferior disease-free survival in patients with squamous cell carcinoma of the head and neck undergoing curative cancer surgery (8). ProT $\alpha$ was regarded as a poor prognostic factor in primary breast cancer, hepatocellular carcinoma, gastric cancer and upper urinary tract cancer, as well as in prostate cancer (7,20-23). In the present study the association of ProTa with squamous cell carcinoma and cigarette smoking was defined in a small sample. However, the underlying mechanism beyond this association requires further examination.

In our previous report on ProT $\alpha$ transgenic mice, increased Smad family member 7 and reduced tissue inhibitor of matrix metalloproteinase-3 were indicated in mice with cigarette smoke extract-induced emphysema (24). A proteomic profile using ProT $\alpha$ as 1 out of 5 biomarkers was valid in predicting the disease-free survival of patients with oral squamous cell carcinoma undergoing curative surgery in India and Canada (25). However, the present study did not examine the association between ProT $\alpha$ and cigarette smoking in oral squamous cell carcinoma (25). ProT $\alpha$ has been revealed to protect cells against apoptosis and oxidative stress (3). Caspase-9 activation negatively regulated by ProT $\alpha$ can inhibit apoptosome formation (26). Elimination of ProT $\alpha$ expression by suppression of RNA has been reported to sensitize cells to ultraviolet irradiation-induced apoptosis (3). In human lung adenocarcinoma A549 cells, human PNAS4 had the ability to induce apoptosis through downregulation of annexin A1 and ProTa. However, no detailed information on the role of ProT $\alpha$ in lung adenocarcinoma was provided in the aforementioned study (26).

In conclusion, the data of the present study indicated that ProT $\alpha$ expression was higher in squamous cell carcinoma of the lung compared with adenocarcinoma. Patients with squamous cell carcinoma and who smoked had higher ProT $\alpha$ scores compared with patients with squamous cell carcinoma and who did not smoke. However, cigarette smoking did not contribute to a difference in ProT $\alpha$ expression in adenocarcinoma of the lung. These results indicate a potential association between ProT $\alpha$ and cigarette smoking in squamous cell carcinoma. However, this result is limited to reflect only the clinical implications of ProT $\alpha$ at present. Therefore, comparing the expression of ProT $\alpha$ in lung cancer and adjacent normal control tissue samples of smoking and non-smoking patients is required to investigate smoking-associated carcinogenesis of squamous cell carcinoma. Further investigations of the clinical impact of ProT $\alpha$ in lung cancer, including a larger sample size of patients with lung cancer, particularly patients with squamous cell carcinoma, are required.

\section{Acknowledgements}

We appreciated the technical support from Professor $\mathrm{Wu}$ CL's Lab and the collection of clinical information by Cancer Center of Chi-Mei Medical Center.

\section{Funding}

The present study was supported by Chi Mei Medical Center (grant nos. CMFHR 10409 and CMFHR 10516).

\section{Availability of data and materials}

The datasets used during the current study are available from corresponding author on reasonable request.

\section{Author's contributions}

YHK and YHF were major contributors in writing the manuscript and analyzing the patient data. CLT, YCS and CFL performed the histological examination. ALS, PW, BHS, CJT and CLW made substantial contributions to study design, data analysis and interpretation, and manuscript organization. All authors read and approved the final manuscript.

\section{Ethics approval and consent to participate}

The study was approved by the Institutional Review Board of the Chi Mei Medical Center (approval no. 10308-002). The condition of inform consent was a waiver documentation of consent, based on the protection of patient identifiable information.

\section{Patient consent for publication}

Not applicable.

\section{Competing interests}

The authors declare that they have no competing interests.

\section{References}

1. Haritos AA, Goodall GJ and Horecker BL: Prothymosin alpha: Isolation and properties of the major immunoreactive form of thymosin alpha 1 in rat thymus. Proc Natl Acad Sci U S A 81: 1008-1011, 1984 
2. Smith MR, al-Katib A, Mohammad R, Silverman A, Szabo P, Khilnani S, Kohler W, Nath R and Mutchnick MG: Prothymosin alpha gene expression correlates with proliferation, not differentiation, of HL-60 cells. Blood 82: 1127-1132, 1993.

3. Jiang X, Kim HE, Shu H, Zhao Y, Zhang H, Kofron J, Donnelly J, Burns D, Ng SC, Rosenberg S and Wang X: Distinctive roles of PHAP proteins and prothymosin-alpha in a death regulatory pathway. Science 299: 223-226, 2003.

4. Pai CW and Chen YH: Transgenic expression of prothymosin alpha on zebrafish epidermal cells promotes proliferation and attenuates UVB-induced apoptosis. Transgenic Res 19: 655-665, 2010.

5. Letsas KP and Frangou-Lazaridis M: Surfing on prothymosin alpha proliferation and anti-apoptotic properties. Neoplasma 53: 92-96, 2006.

6. Mori M, Barnard GF, Staniunas RJ, Jessup JM, Steele GD Jr and Chen LB: Prothymosin-alpha mRNA expression correlates with that of c-myc in human colon cancer. Oncogene 8: 2821-2826, 1993.

7. Jou YC, Tung CL, Tsai YS, Shen CH, Syue-Yi C, Shiau AL, Tsai HT, Wu CL and Tzai TS: Prognostic relevance of prothymosin-alpha expression in human upper urinary tract transitional cell carcinoma. Urology 74: 951-957, 2009.

8. Tripathi SC, Matta A, Kaur J, Grigull J, Chauhan SS, Thakar A, Shukla NK, Duggal R, Choudhary AR, Dattagupta S, et al: Overexpression of prothymosin alpha predicts poor disease outcome in head and neck cancer. PLoS One 6: e19213, 2011.

9. Ha SY, Song DH, Hwang SH, Cho SY and Park CK: Expression of prothymosin alpha predicts early recurrence and poor prognosis of hepatocellular carcinoma. Hepatobiliary Pancreat Dis Int 14: 171-177, 2015.

10. Zhang M, Cui F, Lu S, Lu H, Jiang T, Chen J, Zhang X, Jin Y, Peng $\mathrm{Z}$ and Tang $\mathrm{H}$ : Increased expression of prothymosin- $\alpha$, independently or combined with TP53, correlates with poor prognosis in colorectal cancer. Int J Clin Exp Pathol 7: 4867-4876, 2014.

11. Sasaki H, Fujii Y, Masaoka A, Yamakawa Y, Fukai I, Kiriyama M, Saito Y and Matsui H: Elevated plasma thymosin-alphal levels in lung cancer patients. Eur J Cardiothorac Surg 12: 885-891, 1997.

12. Moody TW, Leyton J, Zia F, Tuthill C, Badamchian M and Goldstein AL: Thymosinalpha1 is chemopreventive for lung adenoma formation in A/J mice. Cancer Lett 155: 121-127, 2000.

13. Sasaki H, Nonaka M, Fujii Y, Yamakawa Y, Fukai I, Kiriyama M and Sasaki M: Expression of the prothymosin-a gene as a prognostic factor in lung cancer. Surg Today 31: 936-938, 2001.

14. Su BH, Tseng YL, Shieh GS, Chen YC, Shiang YC, Wu P, Li KJ, Yen TH, Shiau AL and Wu CL: Prothymosin $\alpha$ overexpression contributes to the development of pulmonary emphysema. Nat Commun 4: 1906, 2013.

15. Sukhacheva EA, Evstafieva AG, Fateeva TV, Shakulov VR, Efimova NA, Karapetian RN, Rubtsov YP and Vartapetian AB: Sensing prothymosin alpha origin, mutations and conformation with monoclonal antibodies. J Immunol Methods 266: 185-196, 2002.
16. Tsai YS, Jou YC, Lee GF, Chen YC, Shiau AL, Tsai HT, Wu CL and Tzai TS: Aberrant prothymosin-alpha expression in human bladder cancer. Urology 73: 188-192, 2009.

17. Greene FL, Page DL, Fleming ID, Fritz AG, Balch CM, Haller DG and Morrow M (eds): AJCC Cancer Staging Manual. 6th edition. Springer Publ. Corp., New York, NY, pp165-178, 2002.

18. Pesch B, Kendzia B, Gustavsson P, Jöckel KH, Johnen G, Pohlabeln H, Olsson A, Ahrens W, Gross IM, Brüske I, et al: Cigarette smoking and lung cancer-Relative risk estimates for the major histological types from a pooled analysis of case-control studies. Int J Cancer 131: 1210-1219, 2012.

19. Ralhan R, Desouza LV, Matta A, Tripathi SC, Ghanny S, Datta Gupta S, Bahadur S and Siu KW: Discovery and verification of head-and-neck cancer biomarkers by differential protein expression analysis using iTRAQ labeling, multidimensional liquid chromatography, and tandem mass spectrometry. Mol Cell Proteomics 7: 1162-1173, 2008.

20. Magdalena C, Dominguez F, Loidi L and Puente JL: Tumour prothymosin alpha content, a potential prognostic marker for primary breast cancer. Br J Cancer 82: 584-590, 2000.

21. Wu CG, Habib NA, Mitry RR, Reitsma PH, van Deventer SJ and Chamuleau RA: Overexpression of hepatic prothymosin alpha, a novel marker for human hepatocellular carcinoma. $\mathrm{Br}$ J Cancer 76: 1199-1204, 1997.

22. Leys CM, Nomura S, LaFleur BJ, Ferrone S, Kaminishi M, Montgomery E and Goldenring JR: Expression and prognostic significance of prothymosin-alpha and ERp57 in human gastric cancer. Surgery 141: 41-50, 2007.

23. Suzuki S, Takahashi S, Takahashi S, Takeshita K, Hikosaka A, Wakita T, Nishiyama N, Fujita T, Okamura T and Shirai T: Expression of prothymosin alpha is correlated with development and progression in human prostate cancers. Prostate 66: 463-469, 2006.

24. Su BH, Tseng YL, Shieh GS, Chen YC, Wu P, Shiau AL and Wu CL: Over-expression of prothymosin- $\alpha$ antagonizes TGF $\beta$ signalling to promote the development of emphysema. J Pathol 238: 412-422, 2016.

25. Chauhan SS, Kaur J, Kumar M, Matta A, Srivastava G, Alyass A, Assi J, Leong I, MacMillan C, Witterick I, et al: Prediction of recurrence-free survival using a protein expression-based risk classifier for head and neck cancer. Oncogenesis 4: e147, 2015.

26. Gou LT, Tong AP, Yan F, Yuan Z, He F, Wang W, Zhou Y, Chen LJ, Tang MH and Yang JL: Altered protein-expressing profile in hPNAS4-induced apoptosis in A549 human lung adenocarcinoma cells. J Cell Biochem 108: 1211-1219, 2009. 